\title{
Action Research to Integrate Science with Mathematics through Garden-Based Learning at the Elementary School Level
}

\author{
Sarah Rummel ${ }^{1}$, James Rye ${ }^{2}$, Sarah Selmer ${ }^{2}$, and Melissa Luna ${ }^{2}$ \\ ${ }^{1}$ North Elementary School, Morgantown, United States \\ ${ }^{2}$ Department of Curriculum \& Instruction/Literacy Studies, West Virginia University, Morgantown, United \\ States \\ Email: jim.rye@mail.wvu.edu
}

\begin{abstract}
Practical action research--an iterative and inquiry-based sequence of study--can help guide collaboration in university-school partnerships, in this case, towards the integration of garden-based learning with core disciplines in the elementary curriculum. The study focuses on grade 3 mathematics instruction about measurement and data, the integration of science standards such as structure and function, and math-science practices of attending to precision, modeling, conducting investigations, and interpreting data. Students collect, graph, and make meaning of data as well as solve a problem related to buoyancy of garden produce. Student performance revealed that the majority of students achieved mastery at the distinguished level in producing scaled graphs; and that considerable scaffolding is necessary for students to adequately attend to precision. A field-tested learning cycle is provided, which can be adapted by elementary teachers for classroom instruction and by teacher educators to model for preservice teachers mathematics-science integration that incorporates school gardening.
\end{abstract}

Keywords: Data, investigation, action research, integration, school garden, elementary, schooluniversity partnerships.

\section{Introduction}

Gardening as a part of the school curriculum is increasing in the United States (Blair, 2009) and worldwide (Muehlhoff and Boutrif, 2010). A review of the research literature by Williams and Dixon (2013) and controlled research by Wells et al. (2015) suggests that school gardening/garden-based learning (GBL) has promise for academic achievement in science and math and in science, respectively. Additionally, GBL responds to calls to increase physical activity and exposure to nature as part of the school day (Rye, O'Hara-Tompkins, Eck, and Neal, 2008; Louve, 2005).

GBL is related most to science, and it presents an ideal context for integrating mathematics and science at the elementary level. Through our university-school partnership, science and mathematics teacher educators have been collaborating with elementary preservice and inservice teachers since vear 2011 to develop a model GBL program in one of the partnership's professional development schools (Westgate Elementary), with the long-term goal of transferring this model to other schools. We have participated in grade-level structured teacher planning and partnered with teachers in providing instruction and writing grant proposals to build our garden infrastructure, which now includes 35 outdoor raised beds, a high tunnel, pollinator and pumpkin patches, composting facility, in-classroom labs and proiect-based curricula.

Given the dearth of practitioner articles that feature strategies for teaching mathematics through GBL, we recently have focused more of our efforts on mathematics learning. Common Core State Standards in Mathematics (CCSSM) content that we have found especially suited to GBL include number and operations (e.g., fraction of seeds that germinate), geometry (e.g., shapes of garden beds), and measurement and data, the latter of which is the focus of this article (Common Core State Standards Initiative, CCSSI, 2010). Herein, we describe the enactment of a learning cycle entitled "A Fruity Investigation" (Figure 1) in a grades 3-4 mathematics class in which students collect, graph and make meaning of data as well as solve a problem, all related to the buovancy of garden produce. Mathematics learning focuses on the content domain of measurement and data (Common Core State 
Standards Initiative [CCSSI], 2010), and the integrated science content includes interactions in ecosystems and structure and function (Next Generation Science Standards [NGSS] Lead States, 2013). Students engage in the mathematics and science disciplinary practices of atttending to precision, modeling with mathematics, planning and conducting investigations, and analyzing and interpreting data (CCSSI, 2010; NGSS Lead States, 2013). At the conclusion of this article, we provide an outline of the preparation and basic steps for conducting each phase of this learning cycle, which emerged from our practical action research (Fraenkel, Wallen, and Hyun, 2015). This learning cycle has utility for elementary teachers and teacher educators, the latter of whom can use it to model and engage preservice teachers in math-science integrated instruction and GBL.

The instruction described by this article also responds to Principles to Action (National Council of Teaching Mathematics [NCTM], 2014), which states that an excellent mathemattics program includes "an effective curriculum [that] incorporates problems in contexts from everyday life and other subjects whenever possible" (p. 4). Food is central to everyday life; mathematics instruction is ideal for incorporating science and in a manner that stimulates inquiry, research and graphing. The study that follows emerged from prolonged engagement between an elementary teacher and university faculty to integrate garden-based learning applications with the core curriculum.

\section{Purpose}

Mathematics is a higher priority than science in the elementary curriculum. In order to increase adoption of GBL by teachers, instruction needs to be more tightly linked to grade-level mathematics standards. This research sought to extend the scope of mathematics instruction appropriate for GBL and further highlight mathematics-science integration in authentic contexts. We aimed to adapt an existing science learning cycle - used in a methods course for preservice teachers - to focus on elementary level mathematics standards about measurement and data, the data being generated from produce grown in school gardens such as the garden at Westgate Elementary. We wanted to learn how best to incorporate grade 3 level instruction on graphing while also reinforcing science content appropriate for the later elementary grades, all in the context of GBL. The field-tested learning cycle that resulted could then be used by a wider audience of elementary teachers and also could serve as an authentic model, for elementary preservice teachers, of a mathematics-science integratedl learning cycle that incorporated dimensions of school gardening.

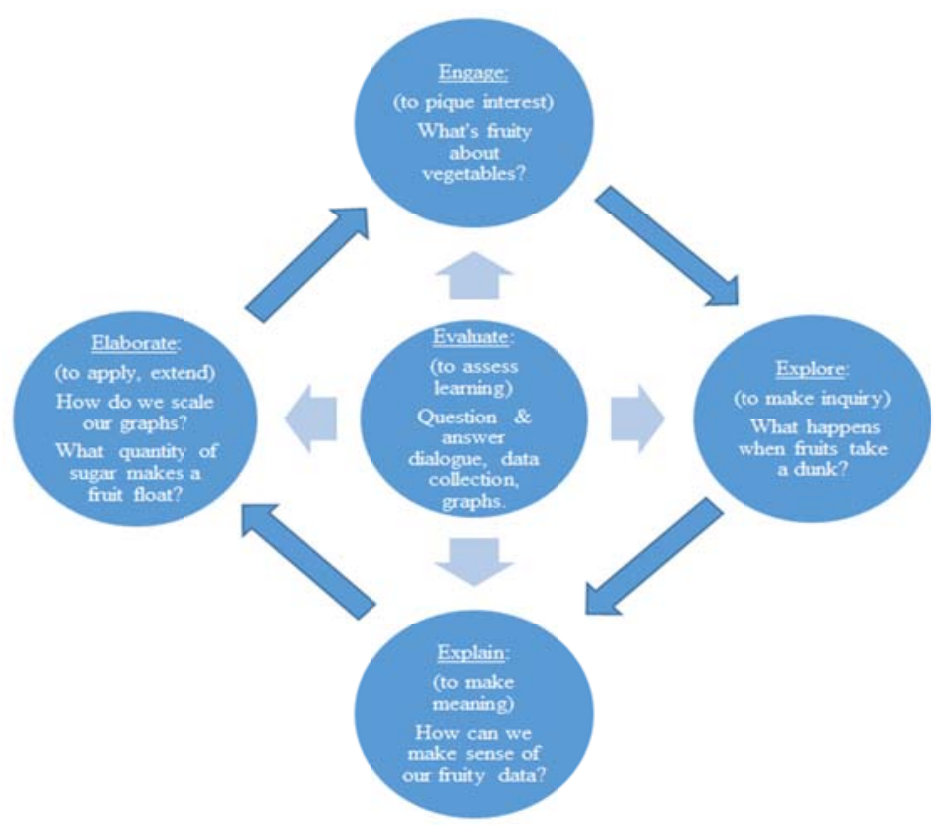

Figure 1. Phases of and questions to drive the learning cycle, A Fruity Investigation. Design of learning cycle based on the 5E Biological Sciences Curriculum Study (BSCS, 2016). 


\section{Methods}

Our study is best labeled as practical action research (Fraenkel, Wallen, and Hyun, 2015) and followed an iterative and inquiry-based sequence of "plan-implement-reflect." Here, the second author of this paper - a university science educator-partnered with a grades 3-4 classroom teacher (Mrs. Rigg) of mathematics. The teacher was the primary instructor, and instruction included some team teaching with the science educator. Each partner scribed field notes of what transpired during instruction, which were subsequently reviewed and utilized in face-to-face meetings and email correspondence to plan each subsequent learning cycle phase (engage, explore, explain, elaborate, with evaluation embedded throughout). The first "round" of this action research sequence took place during Spring, 2015, with the goal to align the learning cycle with grade 4 science standards and field-test the instruction during several class periods. This first round reaffirmed to the partners the strong potential that this learning cycle had for mathematics instruction as well as the degree it could be related to our school garden. The second round occurred during Fall, 2015, where the partnership focused on mathematics content appropriate for grade 3 students enrolled in an advanced (grades 3-4) math course, the integration of science with that mathematics, and the explicit ties to our school garden. Below, we describe the enactment of instruction - the implementation portion of our action research sequence - during Fall, 2015. The enactment spanned approximately seven class periods over a 3 -week timeframe. Planning and reflection were interwoven between each implementation phase, occurring more than once in instances where the phase required more than one class period to complete.

\section{Enactment of Instruction}

\subsection{Engagement Phase: What's Fruity about Vegetables?}

Mrs. Rigg initiates the learning cycle with her third grade students by visiting the school garden to observe what is out there and collect some produce to study (Figure 2). One student quips: "Why are we going to the garden, Mrs. Rigg, this is advanced math class?" Mrs. Rigg explains that we use mathematics to be successful in gardening (e.g., measurement for depth of planting and spacing of plants). Mathematics also can help to quantify the degree of success. While in the garden, students see a variety (shapes, colors) of tomatoes and they spot a half-eaten watermelon that reveals many seeds. Mrs. Rigg challenges students to think about how we know what is a fruit and what is a vegetable. The students head back to the classroom with a pumpkin, watermelon, tomatoes and more and display the harvest (Figure 3). Mrs. Rigg asks students for more observations, which include geometric shapes and dimensions of the produce such as spheres (e.g., melon and pumpkin) and spherical pyramids (e.g., pear tomatoes). The display also presents an opportunity for estimation and measurement. For example, students can estimate the mass in grams of a pepper, weigh the pepper, and solve related one-step problems, such as determining the mass of five peppers.

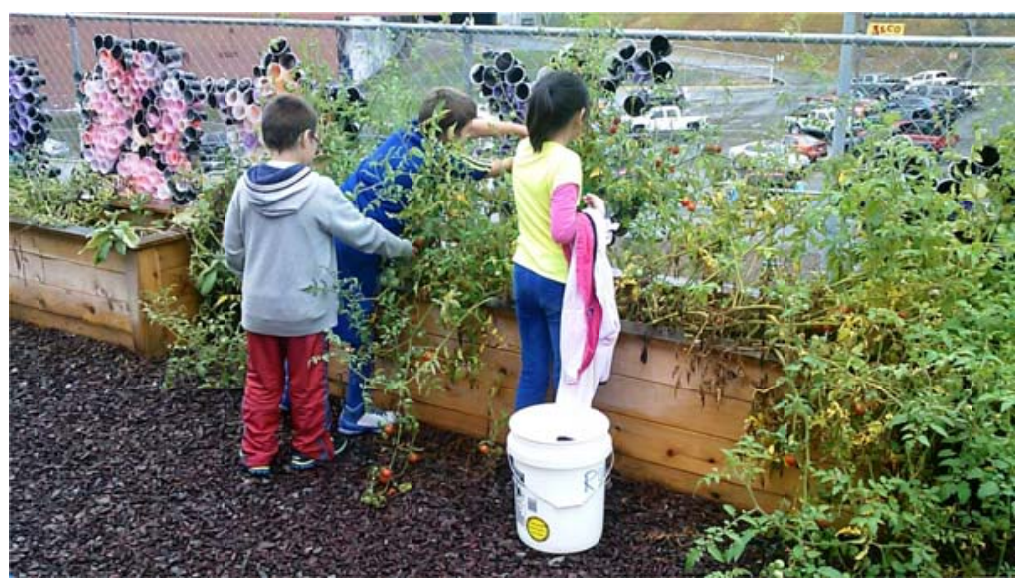

Figure 2. Students harvesting cherry tomatoes from their school garden to explore in our learning cycle. 


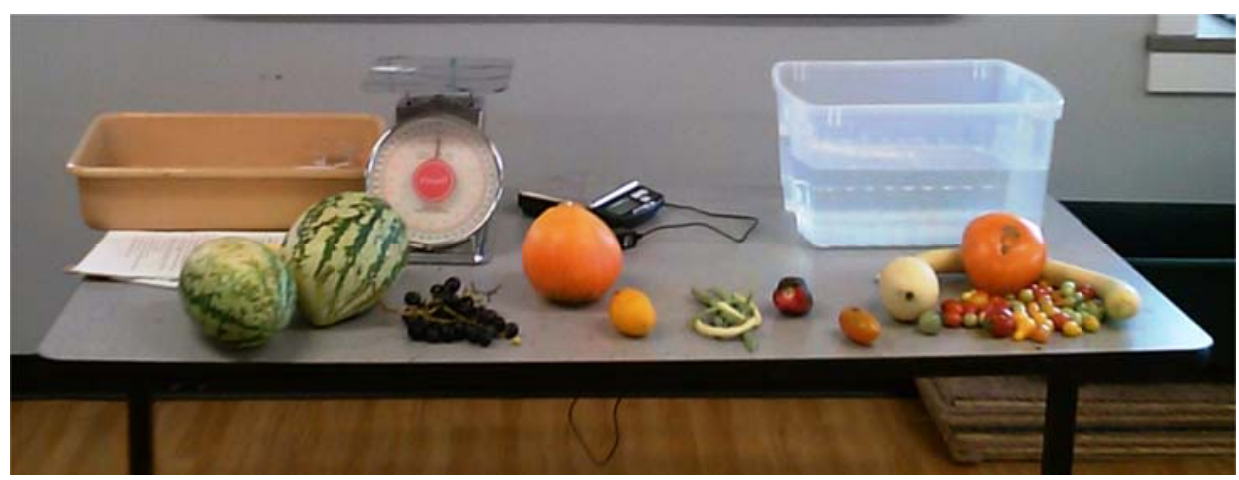

Figure 3. Produce harvested during our trip to the garden.

Mrs. Rigg asks students to return to their thoughts about what makes something a fruit as opposed to a vegetable. She cuts open some tomatoes and beans. Discussion concludes with the fact that any produce containing seeds is a fruit. Mrs. Rigg continues: "What is the purpose of the flesh surrounding the seeds?" Class discussion brings in the concepts of structure and function and ecosystem interactions, including: the flesh protects the seeds; the sweetness of the flesh attracts animals; the animals eat the fruit and excrete the seeds elsewhere, thereby starting the next generation. The engagement concludes by asking "How are fruits like us?" After students volunteer information about water content and aging, Mrs. Rigg introduces another similarity, which provides a bridge to the exploration phase of the learning cycle: "Fruits and humans can sink or float in water. What might help something float?" Discussion ensues about air.

\subsection{Exploration Phase: Fruits Take a Dunk}

Mrs. Rigg employs a derivation of the "predict-observe-explain" strategy (White and Gunstone, 1992; Major, 2006) to structure this phase of the learning. Students generate and record data by exploring the behavior of three different fruits - a green bean, pear tomato, and red grape - when immersed in water. Working in partnerships, each of the 27 students has a chart on which they are to make and record the prediction for both members, share reasons for the predictions, and observe and record what happens ( sink or float) when each fruit is immersed in water. All predictions from all partinerships are recorded on the board (see Figure 4).

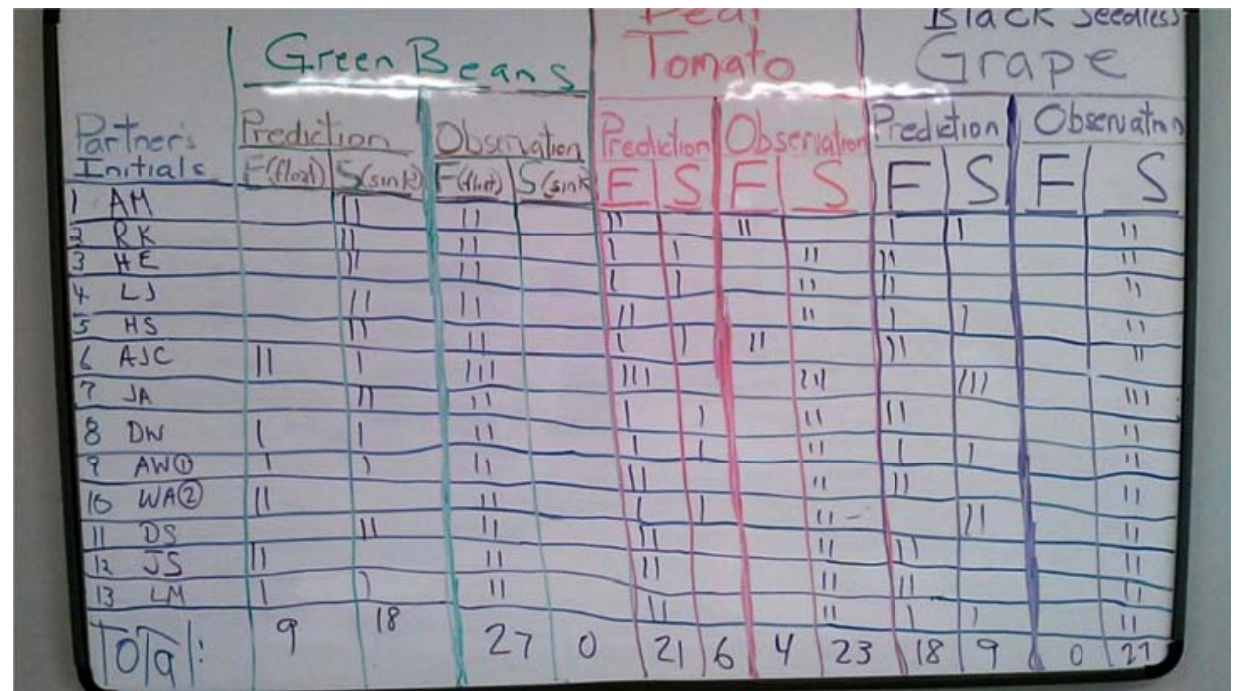

Figure 4. Predictions and observations from each student $(\mathrm{N}=27)$ in all partnerships. Partnership 6 was comprised of 3 students due to the uneven number of students in the class. 
In arriving at the class totals for predictions as well as making sense of all data collected throughout this learning experience, Mrs. Rigg employs four of the Principles to Action teaching practices: posing purposeful questions, promoting reasoning and problem solving, facilitating meaningful discourse, and using and connecting mathematical representations (NCTM 2014). As regards posing purposeful questions that also promote reasoning and problem solving, Mrs. Rigo probes students' thinking about how they can use the sum of one column to determine the total for another: "If "21 students predicted that the pear tomato will float, how many predicted it will sink-without adding the tally marks in the "Sink" column? How did you determine your answer?" As students set about testing their predictions (Figure 5) through immersing fruits in water, the majority discover that their observations differ from their predictions (e.g., for the grape, all 27 students observed "S" [sink] yet 18 had predicted "F" [float]-see Figure 4).

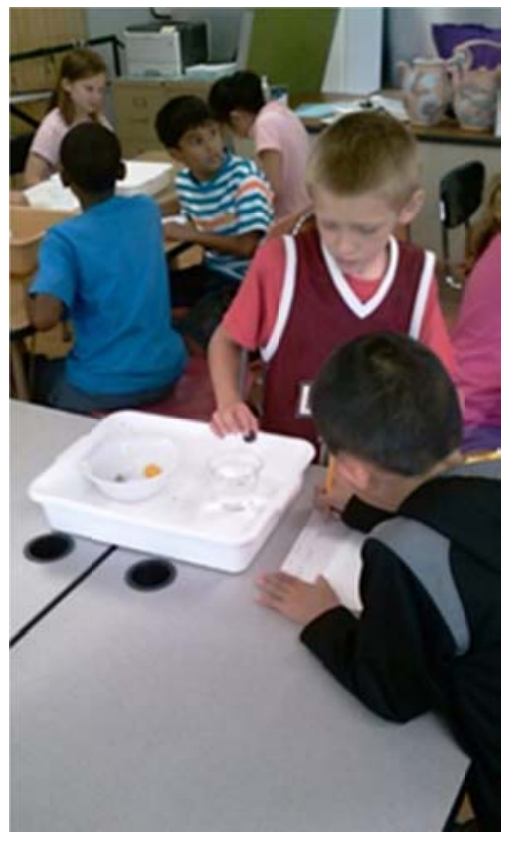

Figure 5. Students testing their predictions about fruits floating or sinking in water.

\subsection{Explanation Phase: Digesting the Fruity Data}

Mrs. Rigg begins the explanation phase by focusing students on their fruity data (Figure 4) and facilitating meaningful discourse: "Come up with one math statement that uses any of the data on the chart to help explain the data." Li shares: "For the green bean, 18 subtract 9 equals 9 so 9 floated." Mrs. Rigg agrees that 9 did float, but explains that we need to change the sentence to state a correct way (attend to precision; CCSSI 2010) to determine that 9 floated. She asks students to determine the total number of predictions that were made for the green bean $(9+18=27)$ and states that we need to change the statement to 27 subtract 18 equals 9. Other students volunteer statements that compare predictions to observations: "The majority of the class said the bean was going to sink but it appeared to float."

Mrs. Rigg asks: "What is an easier way to look at our data [Figure 4]?" Probing and showing graph paper does not result in the desired response ("a graph"), which students should have learned the previous year. Mrs. Rigg states "graphs," and a student volunteers that a bar graph would allow us to compare numbers. Mrs. Rigg explains that we use a bar graph when we want to compare groups or categories, with the names of the categories placed on the x-axis and numbers placed on the y-axis. Mrs. Rigg engages students in constructing a bar graph (single unit) of the data, which also targets the CCSSM practices of attending to precision and modeling with mathematics. The single unit graph served as a refresher of grade 2 standards and scaffolding for making a scaled graph to meet grade 3 standards. Through totaling the number of predictions or observations for any fruit (Figure 4), students 
determine that 27 would be the greatest number on the y-axis and number it accordingly. Mrs. Rigg observes that some students are not attending to precision: They do not place the $\mathrm{y}$-axis numbers on the horizontal lines. Discussion ensues about why this matters.

For determining how many bars will go on the x-axis, Mrs. Rigg engages students in operations and algebraic thinking (CCSSI 2010). For each of the 3 categories (types of fruit), we have two predictions (sink or float) and two observations (sink or float): 3 (types of fruit) x 4 (2 prediction possibilities +2 observation possibilities per fruit) $=12$ bars. Mrs. Rigg illustrates the four bars for the green bean and makes a key for the labels; students do the same on their graph paper (Figure 6).

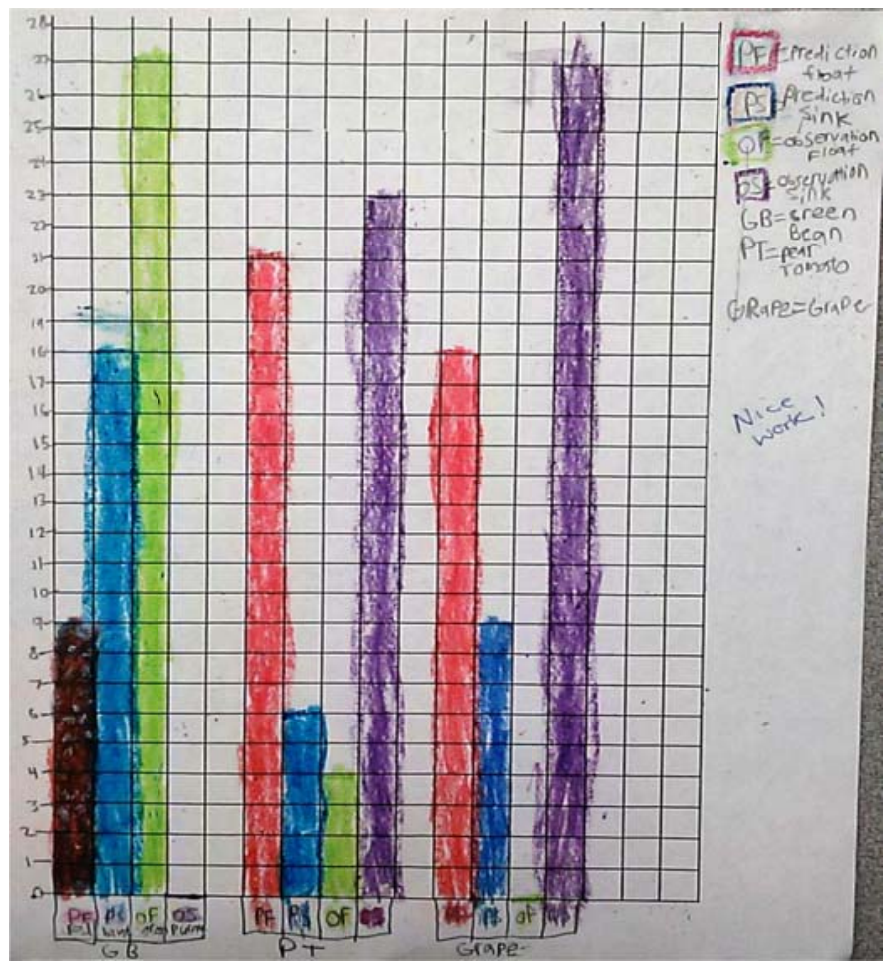

Figure 6. A student's unscaled bar graph accurately representing the fruity data. (The GB prediction float bar is a dark red because the student initially used the wrong color, then corrected it.)

Mrs. Rigg challenges: "What would make this graph easier to read?" Eventually, a student suggests using different colors for each bar, and agreement is reached on the colors (e.g., red for Prediction Float-PF). Mrs. Rigg announces that one student is also color coding her key to match the colors of the bars. Mrs. Rigg continues to provide scaffolding as students construct the pear tomato category, then tells students to construct the grape category on their own. Assessment reveals that the majority of students completed the graph accurately (Figure 6); several did not attend adequately to precision because they left off the key or because their "observation sink" bar for the grape extended only to 26.

\subsection{Elaboration Phase: Scaling the Fruity Data}

Here, students apply what they know from the single unit graph (Figure 6) to produce a scaled graph of the data, which responds to the mathematics teaching practice of connecting mathematical representations (NCTM, 2014). Mrs. Rigg shows students a blank graph with only 25 lines on the y-axis and asks: "What is the biggest number in our data that is shown on the y-axis in the graphs that you just produced [Figure 6]?" "How would you fit that data onto this new graph?" One student responds "count by twos." Mrs. Rigg asks: "Could we also count by fives and tens?" She illustrates that using too large of a number makes it difficult to determine precisely how high to draw the bar or the number that the bar is supposed to illustrate. For example, if one vertical unit equals 10, then the pear tomato quantity of 6 for Prediction Sink (PS) would be squashed into just a portion of only one unit. Through a 
comparison with students' original graphs, Mrs. Rigg illustrates how the height of the bars is shorter on a scaled graph (compared to an unscaled graph) in which 1 vertical unit equals 2 of a quantity. Mrs. Rigg leads the class to produce a scaled graph of the green bean data, asking students where to draw the line for the top of the bars that illustrate data points for Prediction Float (PF, 9) and Observation Float (OF, 27): "Half-way" remark students (They get it!). Students finish the scaled graphs of these three fruits (bean, pear tomato, red grape), then generate additional sink or float data (Figure 7) about green grapes, pea pods, and peas to use in expanding their scaled graphs (Figure 8). Assessment reveals that graphing is "an area of strength" (beyond mastery) for the majority (17/26) of students; 4 of the remaining were "on track" (mastery) and 5 needed improvement, especially in attending to precision.

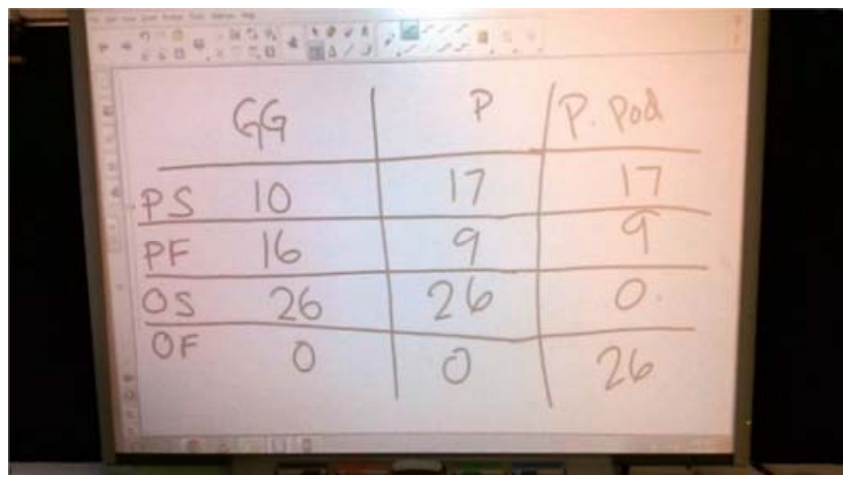

Figure 7. Combined predictions $(\mathrm{P})$ and observations $(\mathrm{O})$ of 26 students as to whether green grapes (GG), peas (p), and pea pods (P. Pod) will sink $(\mathrm{S})$ or float $(\mathrm{F})$ in water.

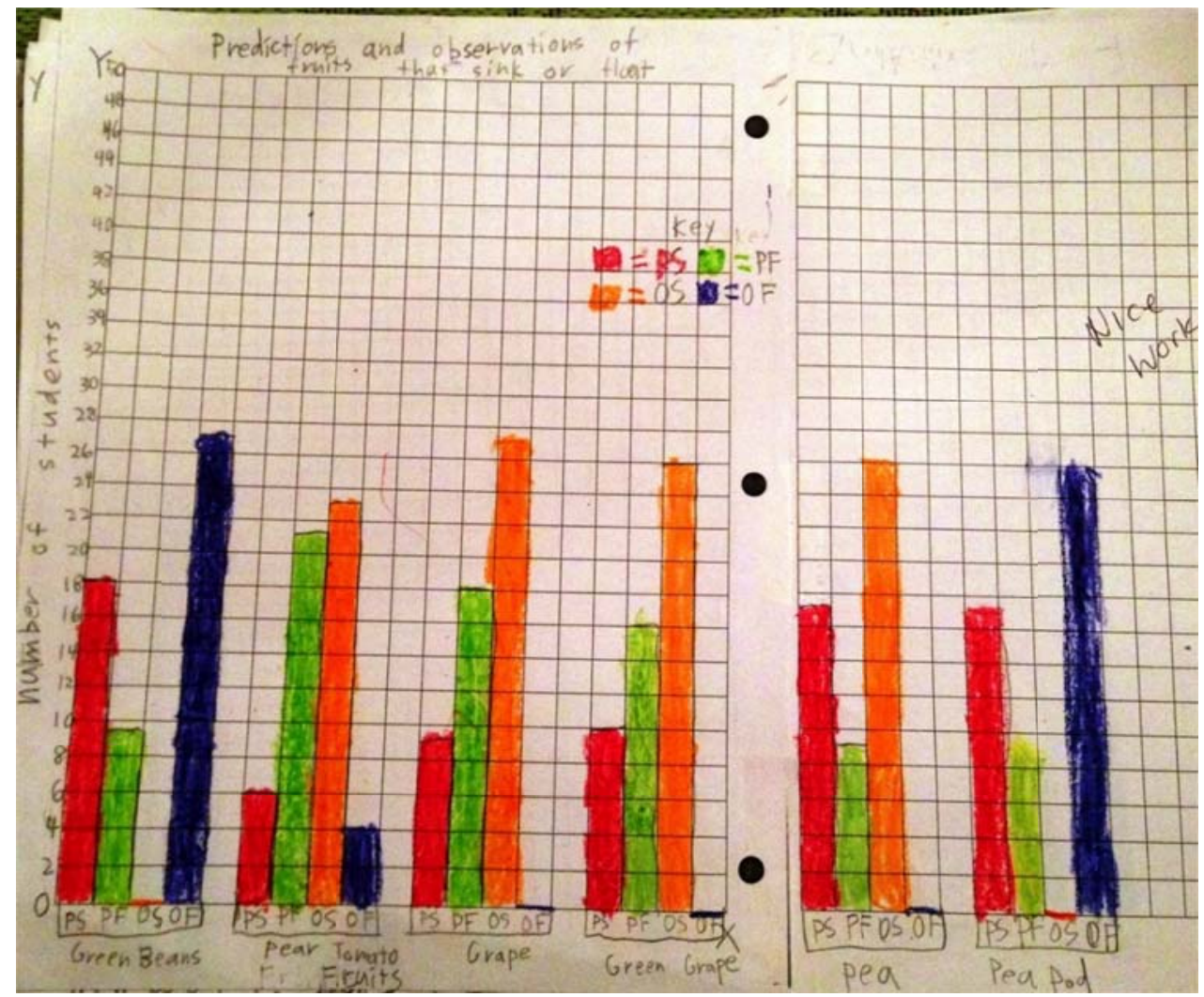

Figure 8. Student's graph assessed as "area of strength" on predictions and observations of fruits sinking and floating in water. (Only 26 students were present for green grape, pea, and pea pod.) 
The completed graphs provide a mathematical representation to continue addressing the standard by engaging students in solving one- and two-step problems (e.g., for the green grapes, what is the difference between the number that were predicted to sink and observed to sink? [27-9=18]; comparing the pea and pea pod data, for which is the difference the smallest between the observation and the "accurate" prediction? [pea: 26-17=9; pea pod: 26-9=17; comparison reveals smallest difference for pea]).

The elaboration phase continues by engaging students in additional research and scaling of graphs, and they also have fun solving a problem about how to make sinking fruits float (Figure 9). Class discussion about what makes fruit float or sink evidences middle school level science understandings in some students, such as the concept of density. Slicing open fruits reveals that the air contained inside some (e.g., a bean pod, core of apple) was one reason to explain floating. Discussion about the grape resulted in lots of talk about water and included that there was no air. It took considerable discussion and prompting (e.g., a grape tastes sweet) for them to suggest that the grape contains sugar. Students then were asked, "What is first observed when sugar is poured into a container of water?" They remarked that the water gets cloudy and the sugar sinks to the bottom. To make a grape float, one student suggests cutting a hole in it, another says to blow bubbles under it, and a third student talks about putting it in juice. Discussion about what's in juice reveals "sugar," so the class decides to give that a try. Our research question eventually becomes: What is the minimum amount of sugar to dissolve in 90 milliliters (3 fluid ounces) of water to make the fruit float?

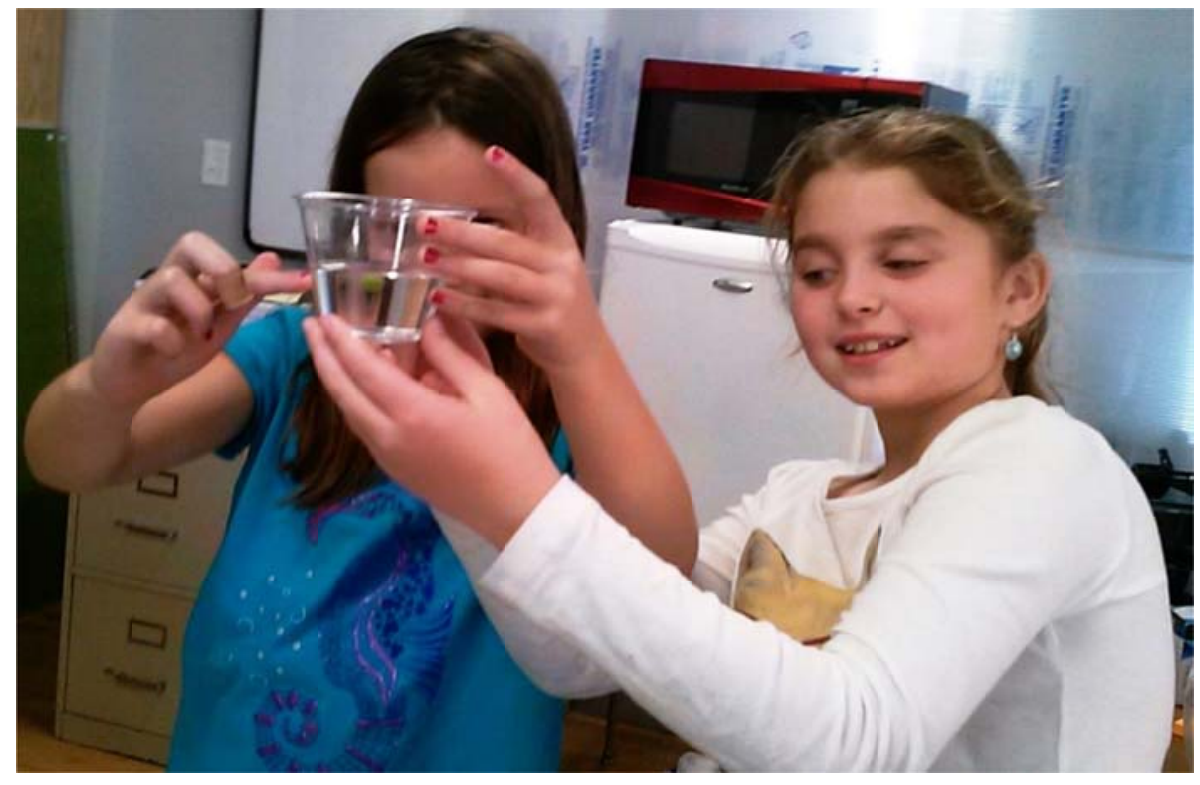

Figure 9. Pea becomes buoyant in $90 \mathrm{~mL}$ of water after dissolving 5 level teaspoons of sugar.

Students measure the sugar in teaspoons (tsp) and test a red grape, green grape, and pea (technically, a seed from the "pea pod" fruit). Mrs. Rigg stresses that in order to compare our findings, each partnership must follow the same procedures: tsp must be level full; observations are recorded only after all sugar has dissolved. Yet, she still observes some students are not being precise in adjusting the quantity of sugar to a level tsp and are recording an observation before dissolving all the sugar. She reiterates the importance of following the same procedures and observes improvements.

After adding and dissolving a few tsp of sugar to test the red grape, one student exclaims, "Look, the water level is going up!" Discussion with students revealed the science terms of mixture and solution and that the sugar is still there even though we cannot see it. The start to end difference in liquid volume provides another learning opportunity in data and measurement: to solve a problem that requires measuring liquid volume (CCSSI, 2010).

After all partnerships finish collecting data, each partnership pools data with all other partnerships to construct three scaled graphs (green grape, red grape, and pea; Figure 10) that illustrate the variance across partners in tsp of sugar needed to make each fruit float. For constructing these graphs, Mrs. Rigg 
shows students how to scale in a different direction: Each vertical unit represents 1/2 as opposed to twice the quantity of the entity for which the y-axis is labeled (tsp sugar). One student observes that this method of scaling "makes the bar go higher" and another states that "it makes it easier to read." In examining all three graphs, a student shares, "Looks like the peas needed less sugar" and another observes "there is one [bar] that is higher for the peas but the average would be lower." Mrs. Rigg queries: "What is an average?" Jollie: "It's what you would usually get." Mrs. Riggs takes this opportunity to begin developing statistical literacy (Franklin et al., 2007) in students through operations and algebraic thinking by calculating the averages of all quantities shown in each of the three graphs and introducing the term "mean." Students also identify the smallest (minimum [min]) and largest (maximum $[\max ])$ quantities in each graph (Figure 11).

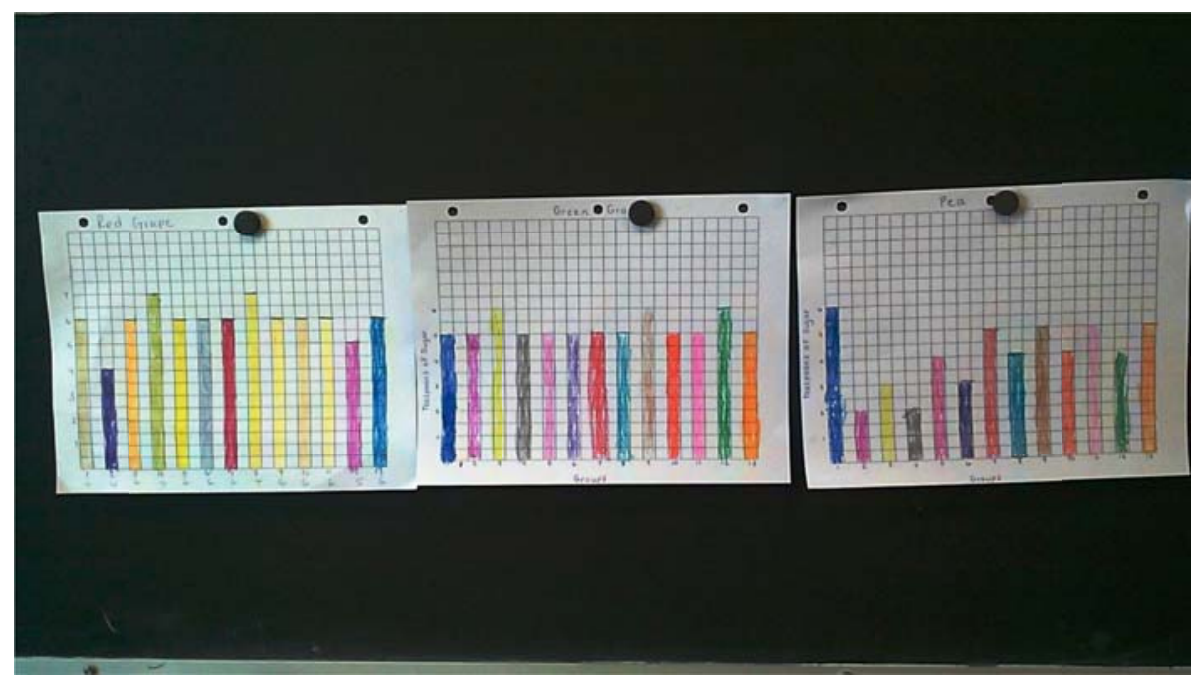

Figure 10. Scaled graphs of quantity (level tsp) of sugar each partnership ( $\mathrm{N}=13$ ) added to $90 \mathrm{~mL}$ water to make a red grape (left), green grape (middle) and pea (right) float.

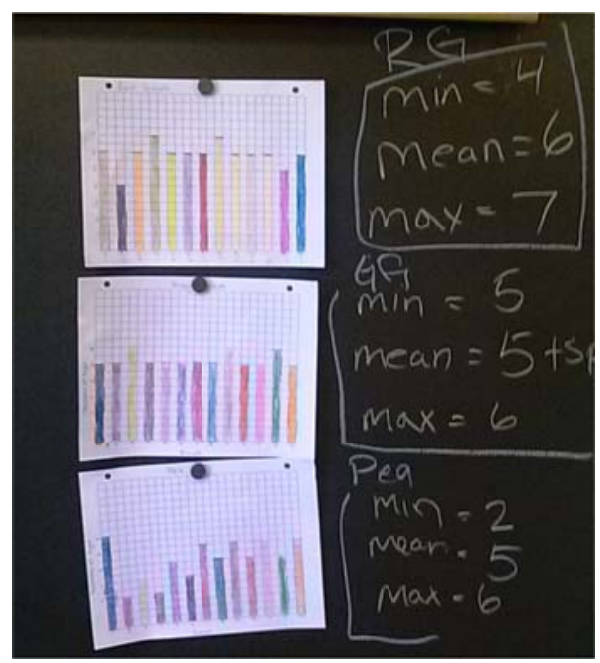

Figure 11. Descriptive statistics (min, mean, max) for tsp of sugar the 13 partnerships added to $90 \mathrm{~mL}$ of water to make a red grape (top), green grade (middle) and pea (bottom) float.

\section{$5 \quad$ Discussion and Conclusions}

Our practical action research of a "plan-implement-reflect" iterative process (Fraenkel et al., 2015) has contributed meaningfully to the scope of mathematical applications for GBL through the adaptation, 
field-testing and refinement of "A Fruity Investigation" learning cycle (Figure 12). Whereas the focus of this particular research was on mathematics and science instruction, the process in which we engaged is applicable to any discipline and benefits multiple stakeholders-in-service and pre-service teachers, university methods instructors, and k-12 students--in a school university partnership.

Our assessment of students' ability to produce scaled graphs (the grade 3 standard) reveals that over 80 percent of students mastered this skill and most (62\%) at the "area of strength" (beyond mastery) level. Implicit in this performance is the success students' also achieved in the science practices of using mathematics and analyzing and interpreting data. This learning cycle experience was the first time that students in this math class were expected to create scaled graphs. One reason to explain why so many students performed beyond mastery may be that they generated the data - they "owned" it - as opposed to just being given a data set to graph. This speculation might be empirically tested, and findings used to justify - or not - the additional classroom time it takes for inquiry-based learning that includes experimental investigations.

Our findings from informal assessment during instruction suggest that grade 3 students need considerable scaffolding in the mathematics practice of "attending to precision," which also is embedded in the science practices of "planning and conducting an investigation" and "obtaining, evaluating and communicating information." Lacking precision in measurement, the results obtained from an investigation are not valid; and a lack of precision in data representation conveys results that are difficult to understand or inaccurate. We recommend to teachers that they think ahead to envision where students may have trouble attending to precision, discuss why precision is important, and be explicit in demonstrating in advance and modeling what it means to be precise. Our informal assessment also suggests that, despite the inclusion of graphing in the grade 2 curriculum, students may enter grade 3 without an understanding of the utility of graphs as a mathematical representation of data.

"Look, the water level is going up!" This student's comment during the elaboration phase of our learning cycle revealed the value of encouraging students to make and share observations, which can be leveraged by the teacher in planning further instruction within and beyond grade level. A strength of the learning cycle format is that observations and findings from the elaboration phase of one learning cycle can lead to questions to investigate in another learning cycle (see Figure 1). For example, a followup learning cycle could engage grade 3 students in number and operation in base 10 (CCSSI, 2010), such as adding and subtracting milliliter measurements up to 1 liter $(1000 \mathrm{~mL})$. Additionally, our action research led to the use by all Westgate Elementary grade 5 teachers of an adapted version of this learning cycle that targeted grade 5 science content about matter and its interactions (5-PS1; NGSS Lead States, 2013) as well as mathematics content, such as converting milliliters (mL) to liters (L) (e.g., $120 \mathrm{~mL}=.12 \mathrm{~L}$ ). A visiting group of school district principals observed the instruction provided by the grade 5 teachers for the purpose of witnessing how GBL can be integrated with the core curriculum. Further, one of our preservice teachers who was substantially engaged in GBL and completing her internship at Westgate presented our work at a national conference (Stone and Rye, 2017).

The elaboration phase of this learning cycle during which students added sugar to water also presents considerable opportunity for mathematics learning in the area of fractions. Pertaining to fractions, students could measure the sugar in fractions of a teaspoon as opposed to using exclusively 1 (or "whole") teaspoon measures. This could lead to the calculation of common denominators (generating equivalent factions) and creating and operating on mixed numbers. It also would enable students to determine more accurately the amount of sugar that is needed to dissolve in water to make the fruit (e.g., grape) buoyant. Additional guidance for quantifying the amount of sugar as well as the resulting volume increases in the sugar solution and relating this to the concepts of density and buoyancy is provided by Rye (1997), which informed various aspects of this learning cycle.

The elaboration phase also reveals the potential to develop statistical literacy in students, which authorities (Franklin et al., 2007) recommend initiating at the elementary level. Mean, minimum, maximum, and range are not set forth as descriptive statistics terms in the elementary level CCSSM. However, the calculation of each can easily be a part of the operations and algebraic thinking content domain (CCSSI, 2010) as evidenced by our dialogue above with Jollie ("but the average would be lower"). Additionally, these are operational terms for the science practices of planning and conducting investigations that are experimental in nature (such as our fruity investigation) as well as analyzing and interpreting data. GBL is abundant in opportunities for conducting authentic experimental investigations at the elementary level. Our findings here reaffirm our previous experiences and 
recommendations (Selmer, Rye, Malone, Trebino, and Fernandez, 2014) that GBL should be leveraged to develop statistical literacy as a part of learning mathematics and doing science.

In summary, this article illustrates one way to further students' understandings about science while teaching mathematics and capitalizing on the current thrust in school gardening (e.g., Wells et al., 2015). This article contributes to the education practitioner literature by describing a novel means through which elementary teachers can integrate science with mathematics in the context of GBL. Additionally, this learning cycle can be utilized by mathematics and science teacher educators in methods courses in which preservice teachers experience it as learners and are asked to reflect on and analyze it in the role of prospective teacher. Specifically, preservice teachers can discuss what makes this an authentic learning context in both math and science and be asked how they could design learning experiences that engage students meaningfully in disciplinary practices and support learning around disciplinary concepts in both math and science. This article sets forth one example of the benefits that can be derived from collaborations between university methods instructors and elementary teachers, and accordingly, strengthens the rationale for practical action research in school-university partnerships.

\section{"A Fruity Investigation" Learning Cycle}

Engage Phase (1/2 to 1,75 -minute class period)

Materials \& Preparation

- You will need assorted produce items - all of which contain seeds: Squash, peppers, tomatoes (regular and small), beans and peas (in pods), grapes (seedless are acceptable), melon, other produce as available/desired with seeds. If you do not have a school garden from which to harvest these items or produce variety is very limited in your garden, obtain these items in advance from grocery store.

- Scale with capacity to mass produce in metric units up to at least 1000 grams.

Procedures

- Lead students on a "fieldtrip" to the school garden to make some observations about "what's out there" and to harvest some produce for investigation and learning mathematics. Prompt students to think about how we know if something is a fruit or if it is a vegetable. If there is no garden to visit at your school, or if you just want to enrich a discussion beyond what is in your garden, show images from the internet of gardens or a farmers market (e.g., http://www.nutrition.gov/farmers-markets).

- Return to classroom and display produce. Continue prompting for observations (e.g., What do you notice? What are similarities and differences?) and sharing thoughts about how we know what is a fruit and what is a vegetable (then explain any produce item that contains seeds is a fruit).

- Ask students to share estimates in grams of different fruits on display; weigh items and have students solve a few one-step word problems using the different masses.

- Ask students to think and share their thoughts about how fruits are like us (humans).

- Conclude with one similarity: They can sink or float in water.

Explore Phase (Students work in partnerships)(1, 75-minute class period)

Materials 8 Preparation

- For each partnership, set up tote tray with: 3 fruits (red grape, small tomato, bean in pod) and a clear plastic cup ( $\sim 8$ fluid ounce size) filled about $3 / 4$ full with tap water.

- Make data collection chart on white/smart board to record, for each fruit, if the fruit sinks or floats (for format, see Figure 4).

Procedures

- Have each student in each partnership copy the chart from the board and write down their prediction as to whether each fruit will sink $(\mathrm{S})$ or float $(\mathrm{F})$ in water.

- Record on class chart all predictions from all students.

- Ask students to volunteer math statements about the predictions.

(Figure 12 continued, next page)

(Figure 12 continued from previous page)

- Distribute tote trays. Instruct partnerships to immerse each fruit (bean first, then small tomato, grape) in water and record observations. Do inside tote tray; no eating fruit!

- Record on class chart all observations.

Explain Phase (2, 75-minute class periods) 


\section{Materials $\&$ Preparation}

- Completed class data chart from Explore phase

- Graph paper and crayons or colored pencils for each student.

Procedures

- Ask students to volunteer math statements about any of the data on the chart to help us make sense of the data; engage students in discussion about the statements.

- Ask students if there is an easier way to look at and make sense of the data.

- Discuss what constitutes a bar graph; guide students through making a bar graph (plus legend/key) for one fruit. Ask students what would make graph easier to read (colors).

- Ask students to graph the other two fruits on their own and turn in for assessment.

Elaborate Phase (3, 75-minute class periods)

Materials \& Preparation

- Completed graphs from Explain phase

- Graph paper and crayons or colored pencils for each student.

- For each partnership, tote tray with: a green grape, pea pod, and pea; clear plastic cup filled 3/4 with water (this set-up is used to collect more predict-observe data)

- For each partnership, tote tray with: 3 fruits (above); 1 clear plastic cup containing 1/2 cup sugar, clear plastic $150 \mathrm{~mL}$ beaker with 90 milliliters water; teaspoon (tsp) for measuring sugar; index card for leveling off tsp.; craft stick for stirring sugar into water (this set-up is used to determine how much sugar is needed to make each fruit float).

Note: If fractions will be incorporated, a set of teaspoon measures will be needed for each partnership capable of measuring to the nearest $1 / 4$ tsp.

Procedures

Scaling Fruity Data

- Distribute to students the graphs that they made in the Explain phase. Ask students: How do we fit our fruity data on graph paper that does not have enough vertical units?

- Explain that we can allow each vertical unit to equal more than 1 of a quantity (in this case the quantity is the number of predictions and observations).

- Guide them through constructing the scaled graph for the green bean data while engaging them in discussion about how high to draw each of the 4 bars.

- When finished with green bean data, ask students: What problems may arise by scaling to 5 or 10 instead of 2? (Illustrate difficulty in drawing or reading with precision the quantity when the data does not fill a full unit at top of bar).

- Ask students to scale the pear tomato and red grape data on their own.

- Provide the tote trays with cups of water and green grape, pea pod, and pea. Follow same procedures as in Engage phase for students (as partners) to collect predict and observe data. Make chart on board that pools data from all students. Ask each student to expand his/her scaled graph with this data; collect graphs for assessment.

Making Fruits Float (Students work in partnerships)

- Challenge students by asking "How can we make a fruit float that sinks in water?"

- Lead them to "add sugar" as a possible answer

- Have them estimate (predict) the quantities of sugar in level tsp that they believe, when dissolved in $90 \mathrm{~mL}$ of water (show beaker with this volume), will make each fruit float.

Note: You may use a greater volume of water (e.g., $120 \mathrm{~mL}$ or $4 \mathrm{fl}$. oz.), but make sure that the beaker you use is large enough so it does not overflow when stirring in sugar.

- Demonstrate procedures: obtain 1 slightly rounded tsp of sugar and level it off over container with index card; add tsp sugar to water, record quantity added; stir until completely dissolved; immerse green grape; record result (sink or float). Tell students to repeat previous steps (don't remove grape) until grape floats. When done with grape, dispose of sugar water (sink) and fruit (trash), rinse and dry beaker, fill with $90 \mathrm{~mL}$ water; repeat previous steps for pea pod and pea. (No tasting; work inside tote tray.)

(Figure 12 continued, next page)

(Figure 12 continued from previous page)

Another Way to Scale (Students work in partnerships)

- Illustrate to students how to produce a scaled graph in which 1 tsp equals 2 vertical units. Ask each 
partnership to add their data (quantity of sugar to make each fruit float) to each of 3 class graphs that you have posted around the room or on the board.

- Utilize graphs to engage students in making meaning of the findings, such as "Which fruit required the most sugar to float? (Students should calculate the average for each fruit; tell students we also call this the mean.) For which fruit did partnerships differ the most on how much sugar it took to make the fruit float? (Students identify the smallest and largest quantities for each fruit; label these as minimum and maximum).

Figure 12. Basic materials, preparation, and procedures for "A Fruity Investigation" that emerged from this action research.

Acknowledgements. We are grateful to school Principal Natalie Webb for allowing us access to the school and her strong support of GBL.

\section{References}

1. Biological Sciences Curriculum Study (2016), BSCS 5E Instructional Model, Available: http://www.bscs.org/bscs-5e-instructional-model.

2. D. Blair (2009), "The child in the garden: An evaluative review of the benefits of school gardening," The journal of environmental education, vol. 40, no. 2, pp. 15-38.

3. Council of Chief State Standards Initiative (CCSSI) (2010), Common Core State Standards for Mathematics, Available: http://www.corestandards.org/assets/CCSSI_Math\%20Standards.pdf.

4. J. Eichinger (2004), Activities for integrating science and mathematics. Pearson.

5. J. Fraenkel, N. Wallen, and H. Hyun (2015), How to design and evaluate research in education. McGraw-Hill.

6. C. Franklin, G. Kader, D. Mewborn, J. Moreno, R. Peck, M. Perry, and P. Scheaffer (2007), Guidelines for Assessment and Instruction in Statistics Education (GAISE) Report: A pre-K-12 curriculum framework. American Statistical Association, Available: http://www.amstat.org/education/gaise/GAISEPreK-12_Full.pdf.

7. R. Louve (2005), Last child in the woods. Algonquin.

8. J. Major (2006), "Will it float?" Science scope, vol. 30, no.2, pp. 22-24.

9. E. Muehlhoff and E. Boutrif (2010). A new deal for school gardens. Food and Agricultural Organization of the United Nations, Available: http:// http://www.fao.org/docrep/013/i1689e/i1689e00.pdf.

10.National Council of Teachers of Mathematics (2014), Principles to Actions: Ensuring Mathematical Success for All. Executive Summary. Available: http://www.nctm.org/uploadedFiles/Standards_and_Positions/ PtAExecutiveSummary.pdf.

11.Next Generation Science Standards (NGSS) Lead States (2013), Next Generation Science Standards: For States, by States. National Academies Press. Available: http://www.nextgenscience.org/next-generation-sciencestandards.

12.J. Rye (1997), "Grape expectations." The science teacher, vol. 64, no. 6, pp. 41-46.

13.J. Rye, N. O'Hara-Tomkins, R. Eck, and W. Neal (2008), "Promoting Youth Physical Activity and Healthy Weight Through Schools." West Virginia medical journal, vol. 104, no. 2, pp. 12-15.

14.S. Selmer, J. Rye, E. Malone, K. Trebino, and D. Fernandez (2014), "What shall we grow in our school garden to sell at the farmers market: Initiating statistical literacy through science and mathematics integration." Science activities, vol. 51, pp. 17-32. DOI: 10.1080/00368121.2013.860418.

15.H. Stone and J. Rye (2017), "A Fruity Investigation: Data and Measurement," Presentation at the NCTM 2017 Annual Meeting and Exposition, San Antonio.

16.N. Wells, B. Myers, L. Todd, K. Barale, B. Gaoloach, G. Ferenz...Aitken, M (2015), "The effects of school gardens on children's science knowledge: A randomized controlled trial of low-income elementary schools," International journal of science education, vol. 37, no. 17, pp. 2858-2878.

17.R. White and R. Gunstone (1992), Probing understanding. Falmer Press.

18.D. Williams and P.S. Dixon (2013), "Impact of garden-based learning on academic outcomes in schools: Synthesis of research between 1990 and 2010," Review of educational research, vol. 83, no. 2, pp. 211-235. 